\title{
Atopya, Kent ve Teknoloji: Atopik Kent Dilinin Değişimi
}

\author{
Gülşah Güleç ${ }^{1}$ \\ ORCID: 0000-0002-8041-2018
}

Öz

Bu yazıda atopik kentin, 20. yüzyılda geliştirilmiş bir kent kuramı olsa da, 21. yüzyılın kentini tanımladığı belirtilir. Atopya, her yer ve hiçbir yer anlamına gelir. Ütopya ve distopyadan farklı olarak geleceğe değil bugüne yöneliktir. Ancak atopya, kent ve teknoloji arasındaki ilişkinin değişmesi, bugünün kentini tanımlayan atopik kentin kavramsal çerçevesini değiştirmektedir. Yeni bir atopik kent dilinin ve kuramının ortaya çımasını să̆layan bu kavramsal değişim, yazı kapsamında, fiziksel mekân yerine siber mekânın, meta yerine datanın, ulaşım ağları yerine iletişim ağlarının, süpermodernizm yerine hipermodernizmin, panoptik yerine sibernetiğin, nesne yerine imgenin, deneyim yerine izlenimin ve kent peyzajı yerine data peyzajının geçmesiyle örneklendirilmiştir. Atopik kent dili özellikle 1990l yıllardan itibaren bilgisayar teknolojisinde yaşanan gelişmelerle birlikte önemli bir değişim geçirmiştir. 2000li yıllarda ise atopik kentler artık bilgisayar teknolojisi aracılığıyla sanal bir ortamda üretilmektedir. Aynı ortamda aynı araçlarla üretiliyor olmaları onları benzeştirmiş, hatta aynılaştırmıştır. Kentlerin aynılaşma süreci, yerle yeni bir ilişki kurulmasın;; böylece 21. yüzyılın atopik kentinin ve kent dilinin ortaya çıkmasını sağlamıştır. Bugünün kentini anlamamız için öncelikle bu dili bilmemiz ve anlamamız gerekir. Bu nedenle, yazı atopik kent dili ve bu dilin değiş̧imi üzerine geliştirilmiştir.

Anahtar Kelimeler: Atopya, atopik kent, kent dili, kent kuramı, teknoloji

1 Öğr. Gör. Dr., Gazi Üniversitesi, E-mail: gulsahgulec@gazi.edu.tr

idealkent @ Kent Araştırmaları Dergisi (Journal of Urban Studies)

http://idealkentdergisi.com

Geliş Tarihi Received Date: 14.05.2020 Kabul Tarihi Accepted Date: 08.12.2020 


\title{
Atopia, City and Technology: The Change of the Atopic City Language
}

\author{
Gülşah Güleç² \\ ORCID: 0000-0002-8041-2018
}

\begin{abstract}
It is discussed in this paper that atopic city, even if it is developed as an urban theory in the 20 th century, defines the city of the 21st century. It refers to every place and no place. It is conceptually different from utopia and dystopia, because it focuses on today not future. However, the changes in the relations of atopia, city and technology lead the conceptual framework of atopic city to change as well. Those changes are discussed through the shift of physical space to cyber space, meta to data, transportation networks to communicational networks, supermodernism to hipermodernism, panoptic to cybernetic, object to image, experience to impression, and cityscape to datascape in the paper. The language of the atopic city is significantly changed due to the developments in the computer technology in the 1990s. Atopic cities are designed computationally within a virtual environment in the 2000s. Those cities are generally designed by the same tools and in the same environment. That computational design process enables a new atopic city language to be created. We need to understand that language to understand today's city. The paper is therefore based on the atopic city language, and the change of that language actually.
\end{abstract}

Keywords: Atopia, atopic city, urban language, urban theory, technology

${ }^{2}$ Instructor Dr., Gazi University, E-mail: gulsahgulec@gazi.edu.tr

idealkent @ Kent Araştırmaları Dergisi (Journal of Urban Studies)

http://idealkentdergisi.com

Geliş Tarihi Received Date: 14.05.2020 Kabul Tarihi Accepted Date: 08.12.2020 


\section{Giriş}

... yeni bir dil yaratma sürecindeyim.

Söylememiz gerekeni sonunda söyleyebilecek bir dil.

Çünkü sözcüklerimiz artık bu dünyaya uymuyor.

Nesneler birer bütünken sözcüklerimizin onları ifade edebileceğine emindik. Ama bu şeyler yavaş yavaş birbirinden koptu, parçalandı, karmaşa içinde yuvarlandı. Sözcüklerimiz ise aynı kaldı. Onlar yeni gerçeğe uyum sağlamadilar. Oysa sözcükler değiş̧ebilirler. Problem, bunun nasıl ortaya koyulacağında.

Paul Auster'ın Cam Kent (City of Glass) adlı kitabından, Can Yayınları, İstanbul, 2016

Atopya, kent ve teknoloji ilişkisinin tartışıldığı bu yazının amacı yeni bir kent kuramı önermek ya da geliştirmek değildir. Bunun yerine, atopyanın 21. yüzyılın kentini tanımladığını ortaya koymaktır. Atopya, yeni bir kavram olmamakla birlikte, bu yüzyılın gelişmiş bilgisayar teknolojisi atopyanın yeni kavramlarla yeniden tanımlanmasını ve tartışılmasını sağlamıştır. Böylece atopik kent dili ve kuramı değişime uğramıştır.

Atopya kavramı çoğu zaman yersizlik (placelessness) ile ilişkilendirilmiştir. Mimarlık alanında bu kavram, Gregotti tarafından, hiçbir yer (no place) olarak tanımlanmıştır (Gregotti, 2000/2016). 19901ı yıllarda ise alışveriş merkezleri, akaryakıt istasyonları, oteller, havaalanları gibi her yerde olan yerler hiçbir yer olarak tartışılmıştır (Koolhaas, 1998). Böylece atopya, hiçbir yer (no place) ve her yer (every place) olarak görülmeye başlamıştır. 2000li yıllarda da genellikle her yer ve hiçbir yer olarak görülen atopya, yer kavramının yeniden tanımlanmasına yol açmıştır. Dahası atopya, yerin yok olmasını değil yeniden yorumlanmasını sağlayan bir kavram halini almıştır (Millet, 2013). Yer, mimarlıkta önemli bir tartışma konusudur. Mimarlık nesnesi ve yeri arasında bugüne kadar çeşitli ilişkiler kurulmuştur. Bu ilişkiler, çoğu zaman, mimarlığın yeni bir yer yaratmasına neden olmuştur. Hatta, bu nedenle, mimarlığın yer yaratımı (creation of place) olduğu öne sürülmüş̧tür (Ots, 2011). Ancak mimarlikta yersizlik (placelessness) ve yersiz yurtsuzlaşma (deterritorializition) gibi kavramların sıklıkla kullanılmaya başlaması, yer yaratımının ve yere ilişkin yaklaşımların değiştiğini ortaya koymuştur. Bunlar, aynı zamanda, atopyayı tanımlamak için kullanılan kavramlardır. 
Deleuze ve Guattari, yersiz yurtsuzlaşma kavramını kapitalizmle ve küreselleşmeyle ilişkilendirerek kullanır. Kapitalizm, iş gücünün ve paranın yerinden edilmesine; yani, yersiz yurtsuzlaşmasına yol açmıştır. Yine de bunlar, kapitalist ve küresel dünyada kendilerine yeni bir yer edinmeyi başarmıştır. Bu nedenle, Deleuze ve Guattari yerinden edilmeyi (deterritorialization) ve yer edinmeyi (reterritorialization) art arda gerçekleşen süreçler olarak ele alır (Deleuze, Guattari, 1980/1987). Bu süreçler, yerle kurulan yeni ilişkileri gündeme getirmektedir. Atopya kavramı ise bu ilişkiler çerçevesinde yeni tanımlar edinmektedir. Böylece kavramsal çerçevesi değişmektedir.

Yazıda atopyanın değişen kavramsal çerçevesi, kentle ve teknolojiyle ilişkili olarak ele alınmaktadır. Bu çerçevenin atopik kent dilini oluşturduğu ortaya koyulmaktadır. Ancak atopik kentin dili bilgisayar teknolojisinin gelişmesiyle birlikte önemli bir değişim geçirmiştir. Öyle ki, 21. yüzyılın atopik kentinde fiziksel mekân yerine siber mekândan, meta yerine datadan, ulaşım ağları yerine iletişim ağlarından ya da kent peyzajı yerine data peyzajından söz edilmektedir. Yani, atopyanın kavramsal çerçevesinin yeni yüzyılın yeni kentini; başka deyişle, kentin yeni dilini ve özelliklerini ortaya koyacak şekilde değiştiği görülmektedir. Bu değişim atopya, kent ve teknoloji ilişkisinin de değiştiğine işaret etmiştir.

\section{Atopya, Kent ve Teknoloji}

Kentlerde, geçtiğimiz yüzyıldan bu yana, yerle yeni ve çok çeşitli ilişkiler kurulmaktadır. 20. yüzyılda özellikle ulaşım teknolojisinde, 21. yüzyılda ise iletişim teknolojisinde yaşanan gelişmeler bu ilişkilerin değişmesine yol açmıştır. Gelişen ulaşım teknolojisi bir yerden diğerine hızla ve kolaylıkla ulaşılmasını, iletişim teknolojisi ise ulaşımın çok daha büyük bir hızla ve iletişim yoluyla olmasını sağlamıştır. Son yıllarda internetin yaygınlaşmasıyla birlikte iletişim teknolojisi kentleri birer sanal gerçeklik ağına dönüştürmüştür (Frampton, 2008). Bu dönüşüm, iletişim ağı toplumunun (network society) ortaya çıkmasına neden olmuştur. İletişim ağı toplumu, içinde bulunduğumuz bilgi çağının etkileşimsel ve iletişimsel toplum modelini tanımlamaktadır (Castells, 2007). Ancak kentler -buna atopik kentler de dahildir- yalnızca teknolojik değil aynı zamanda sosyolojik, ekonomik, politik, topografik ve demografik bir değişim sürecine bağlı olarak değişmekte ve kendisini yenilemektedir.

Sosyolojik değişim, bildiğimiz gibi, toplumsal değişimi ifade etmektedir. Toplumlar arasındaki ilişki ve toplum modeli teknolojik araçların, özellikle 
de iletişim araçlarının yaygınlığına ve yetkinliğine bağlı olarak değişim göstermektedir. Bu araçlar nedeniyle toplumsal farklılıklar gittikçe azalmakta, farklı toplumlar arasındaki iletişim ve etkileşim ağı yeni toplum modellerinin oluşmasını sağlamaktadır. Böylece ekonomi modelleri de yeniden oluşmaktadır; hatta ekonomiye artık kitle iletişim ağı ve araçları yön vermektedir. Bu nedenle küresel ekonomi piyasasından ve bu piyasanın tüm toplumları etkisi altına aldığından söz edilmektedir. Bununla birlikte, dünyada yeni ekonomi politikaları geliştirilmektedir. Dünyanın farklı yerlerindeki kentler, bugün neoliberalizm olarak anılan; küreselleşmenin ve kapitalizmin kentler üzerindeki aynılaş(tır)ma etkisinin artmasına yol açan yeni ekonomi politikalarından etkilenmekte, bu politikaların etkisiyle yönetilmektedir. Kentlerin yapılaşma biçimi ve süreci, neoliberal ekonomi politikalarıla belirlenmektedir (Colas, 2005). Bu süreç, kentlerde önemli topografik değişimlerin ortaya çıkmasını sağlamaktadır. Öyle ki, kentlerin silueti yeni inşa edilen, ancak yeriyle ya da çevresiyle dikkate değer bir ilişki geliştirmeyen büyük ölçekli yapılarla birlikte değişime uğramaktadır. Söz konusu değişimler, kentlerin nüfus yapısının da değişmesini kaçınılmaz kılmaktadır. Özellikle büyük kentlerde her geçen gün artmakta olan nüfus yoğunlukları yaşanmaktadır. Dünyada yaşanan savaşlar, terör saldırıları, salgın hastalıklar ve açlıklar ise kentlerin nüfus yoğunluklarını değiştiren; yani, demografik değişimleri tetikleyen başlıca nedenler olarak karşımıza çıkmaktadır. Tüm bu değişimler kenti, mimarlığı, yeri ve bunlar arasındaki ilişkileri değiştirmektedir. Yazıda 21. yüzyılın kentini tanımladığı belirtilen atopik kentin dili bu değişimlerden etkilenmektedir.

Atopyayı hiçbir yer olarak tanımlayan Gregotti, bu kavramı locus (Latince) ve topos (Yunanca) sözcükleriyle ilişkilendirmiştir. Bu sözcüklerin her ikisi de yer anlamına gelir. Ancak bunlar, Gregotti'ye göre, kutsallaştırılmış yerlere işaret etmek için kullanılan sözcüklerdir. Atopya ise aksine kutsal olmayan, hatta sıradan yerler için kullanılır (Gregotti, 2000/2016). Atopyanın hiçbir yer ve her yer olarak yeniden tanımlanması, siradanlık (banality) kavramının yanı sıra genellik (generality) kavramıyla da tartışılmasına yol açmıştır. Bu tartışma, jenerik kent (generic city) kuramıla ortaya koyulmuştur (Koolhaas, 1998). Jenerik kent, atopik kentle benzer özelliklere sahiptir. Dahası, bir tür atopik kent olarak kuramsallaştırıldığı söylenebilir.

Koolhaas'ın 20. yüzyılın sonlarında ortaya koyduğu jenerik kent kuramı, bilgisayar teknolojisiyle ve teknolojide yaşanan gelişmelerle yakından ilişkilidir. Bu kurama göre, jenerik kent teknolojik bir kenttir. Teknoloji, jenerik kentin yerinin olmamasına ya da yersiz olmasına aracılık etmiştir. Teknolojik 
araçların jenerik kentin yer ile ilişkisinin koparması onu hem her yerde hem de hiçbir yerde olabilecek bir kent modeli haline getirmiştir. Bu açıdan jenerik kent, atopik kentle benzer özelliktedir. Koolhaas, jenerik kenti tartışırken bu kentin havaalanları, alışveriş merkezleri, rezidanslar ve gökdelenler gibi her yerde olan binalardan oluştuğuna değinmiştir (Resim 1). Jenerik kent, ona göre, 21. yüzyılın kentidir. Bu yüzyılın eylemi ise alışveriştir. Her yerde alışveriş yapılır. Bu yüzden her yer, Koolhaas tarafından, hiçbir yer olarak tanımlanir (Koolhaas, 1998).

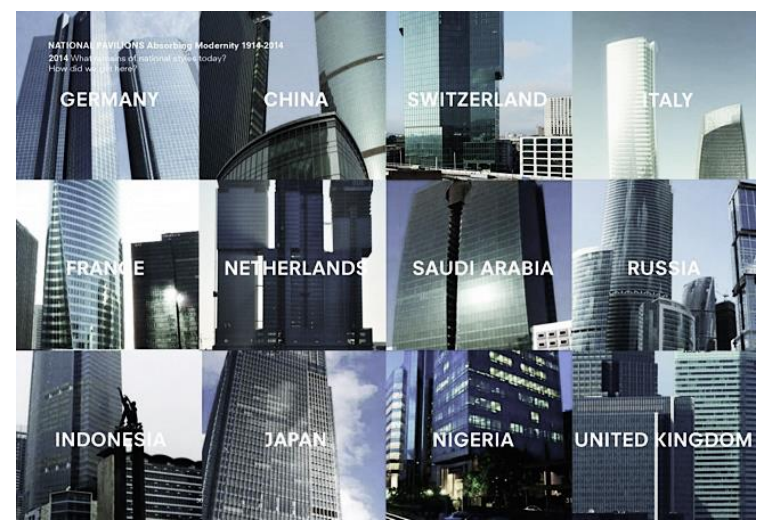

Resim 1. Jenerik kent (Ramchurn, 2020)

Alışveriş, tüketim toplumunun olmazsa olmazıdır. Jenerik kent gibi, atopik kent de tüketim toplumunun kent modeli olarak ele alınır. Bu nedenle, atopik kentte nesne yerine metadan söz edilir (Leite, 2016). Nesne, üretilen ve tüketilen bir metaya dönüşmüş; yani, metalaşmıştır. Mimarlık nesnesi de meta halini almıştır. Hatta son yıllarda bilgisayar teknolojisinde yaşanan gelişmelerle birlikte nesnenin ve metanın yerine data geçmiştir. Böylece atopik kentte artık data üretimi yapılmaktadır. Data, 21. yüzyılın atopik kentini tanımlar ve tartışırken yeni kavramların kullanılmasını sağlamıştır. Data peyzajı (datascape) bu kavramlardan biridir (Ots, 2011). Bu, dijital verilerin oluşturduğu yeni bir kent peyzajıdır. Veriler değiştiğinde kent peyzajı da değişir (Resim 2). Data ya da veri peyzajı denilen yeni kent peyzajında olaylar düzenlenmemiş örüntüler içinde gerçekleşir. Bu nedenle, data peyzajı başlang1cın kendisi olarak değerlendirilir (Maas, 1999). 


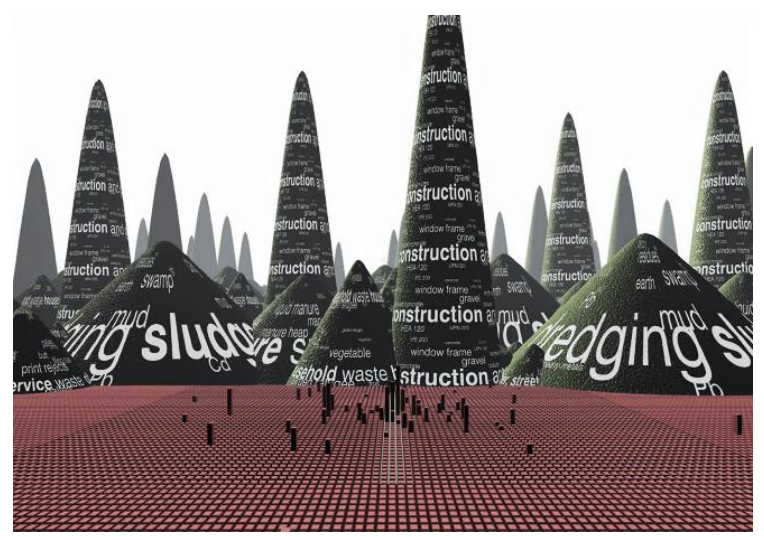

Resim 2. Data kent (MVRDV, 2020)

Data peyzaj1, kentte görünürlüğü arttırmış; herkesin ve her yerin görünür ve izlenir hale gelmesini sağlamıştır. Bugünün atopik kentinin tam da böyle bir peyzajı vardır (Leite, 2016). Bu yüzden, daha önce panoptik olarak tanımlanan atopik kentin bugün daha çok sibernetik olduğu anlaşlır. Foucault tarafından bir tür hapishane olarak tanımlanmış olan panoptikon, insanların sürekli gözetim altında tutulmasını sağlayan mekânsal bir oluşumu ifade etmektedir (Foucault, 1975/1992). Atopik kentte de insanlar benzer bir göz hapsinde oldukları için bu kentin panoptik olduğundan söz edilmiştir. Ancak panoptik gözetim son yıllarda sibernetik iletişimle yer değiştirmiş gibi görünmektedir. Sibernetik, insanlar arasındaki iletişim ve etkileşim ortamına işaret etmektedir. Sibernetik etkileşimlilik, 20. yüzyılın sonunda artı̧̧ göstermiş; 21. yüzyılda ise en yüksek düzeyine erişmiştir (Virillio, 1999/2005). Herkes, her yer ve her şey sibernetik iletişimin ve etkileşimin olduğu kentte bir panoptikonun içindeymiş gibi izlenebilmektedir. Bu, aynı zamanda, fiziksel mekânın yerine siber mekânın geçtiğinin bir göstergesidir. Siber mekân, sanal bir ortamda bilgisayar verileriyle oluşturulur. Yani, gerçek değildir (Mitchell, 1996). Yine de son ylllarda gerçek kentin (real city) yerini sanal kent (virtual city) almıştır (Resim 3). Sanal kent ise yersiz yurtsuzlaştırılmış bir data kent (data city) olarak kavramsallaştırılmıştır (Virilio, 1999/2005). 


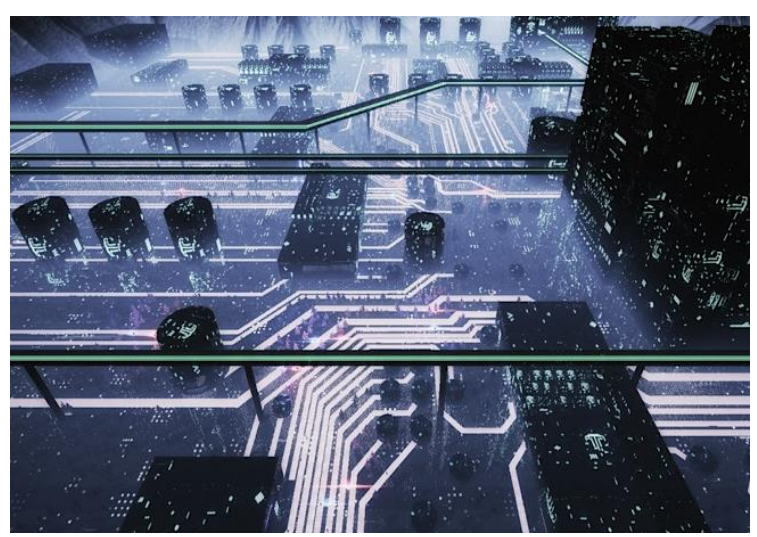

Resim 3. Sanal kent ya da data kent (Liu, vd., 2020)

Burada sanal kent ya da data kent kavramları, bugünün hiçbir yerde ve her yerde olabilecek atopik kent modelini ifade etmek üzere kullanılmıştır. Diğer yandan, atopik kentler çoğunlukla ütopik ya da distopik kentler olarak anılmaktadır. Barthes ise atopyanın ütopyadan farklı olduğunu savunmaktadır. Ona göre, atopya ütopyadan üstündür; çünkü ütopya, var olan dünyanın karşıtı olan ideal bir dünya yaratmayı, atopya ise var olan dünyayı olduğu gibi kabul edip yorumlamayı gerektirir (Barthes, 1977/1994). Gregotti de atopya ile ütopyanın ve distopyanın birbirinden farklı olduğuna işaret etmektedir. Ütopya ve distopya genellikle geleceğe yönelirken; atopya bugüne odaklanır. Ütopya iyi, eşit ve adil bir dünyayı, distopya ise bunun karşıtını ifade ederken atopya yerden kopmuş bir dünyaya karşıllk gelir. Buna dayanarak Gregotti, sanılanın aksine, atopyanın ütopya ya da distopyanın eşiti ya da ön koşulu olmadığını belirtir (Şekil 1). Ancak her biri için güçlü bir kent imgesi yaratmak gerekir (Gregotti, 2000/2016).

\section{\begin{tabular}{l|l} 
Atopya $\neq$ Ütopya & $\begin{array}{l}\text { Atopya }=\text { Hiç bir yer } \\
\text { Atopya } \neq \text { Distopya }\end{array}$
\end{tabular}}

Şekil 1. Atopya nedir, ne değildir?

Atopik kent imgesi ve modern kent imgesi arasında benzerlik olduğu düşünülmektedir (Resim 4, 5). Modernizmin tamamlanmamış bir proje; atopik kentin ve atopik mimarlığın ise bu projenin uzantısı olduğu öne sürülmektedir (Gregotti, 2000/2016). Modernizm, kentlerin tanınır özelliklerini; yani, kimliklerini yok ettiği için onları hem hiçbir yere hem de her yere dönüştürmüştür (Koolhaas, 2014). Hiçbir yer ve her yer olan modern kentlerin kimlikleri yoktur. Kentin dili kimliksizlik ve yersizlik üzerine kuruludur. Bu dil, 
Herzog ve De Meuron'un ayırt edilemez kent (indistinguishable city) kuraminı akla getirmektedir. Ayırt edilemez kent kuramı, Koolhaas'ın jenerik kent kuramında olduğu gibi, kentlerin birbirinden ayırt edilemeyecek kadar benzeştiğini; hatta aynılaştığını ortaya koymuştur (Herzog ve De Meuron, 2008).

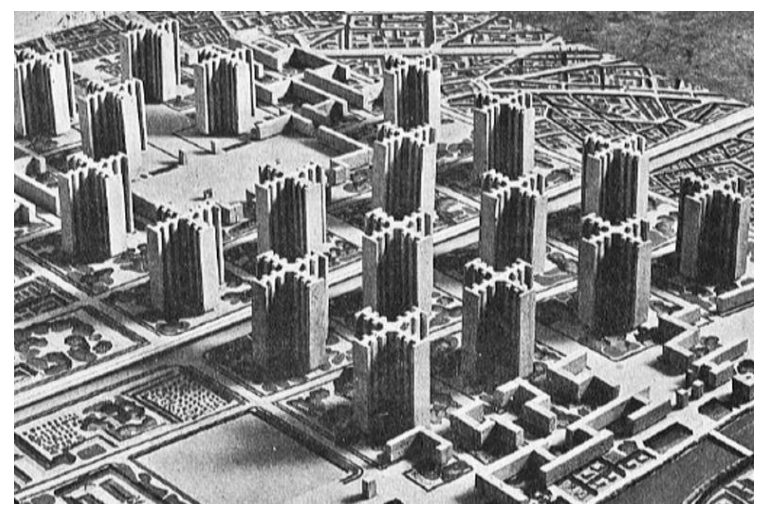

Resim 4. Modern kent (Price, 2020)

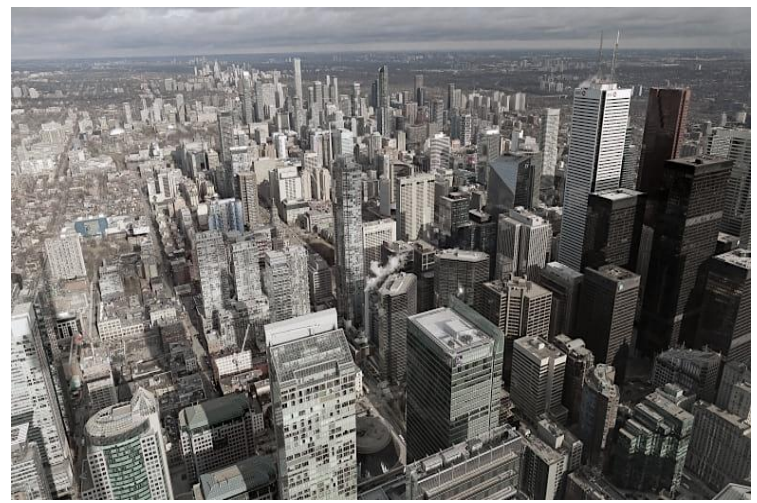

Resim 5. Atopik kent (Ricci, 2020)

Herzog ve De Meuron, bugün bildiğimiz kent kuramlarının geçerliliğini yitirdiğini; 21. yüzyılın kentinin yeni kuramlarla yeniden kavramsallaştırılması ve biçimlendirilmesi gerektiğini savunmuştur. Koolhaas gibi onlar da kentlerdeki esas eylemin alışveriş olduğunu; kentlerin bu esasa göre oluştuğunu düşünür. Kentsel oluşumda dijital teknolojinin önemli bir rolü olmuş; başka deyişle, dijital teknoloji yeni bir kent modeli oluşturmuştur. Bu aynı zamanda yeni bir kent dili demektir. Ayırt edilemezlik ve aynılık gibi kavramların öne çıktığı bu dil, genel olarak kentlerin kimliksiz ve yersiz olduğunu ifade etmektedir. Kimliksizlik ve yersizlik, Herzog ve De Meuron'a göre, kentlerin ayırt edici değil birbirinin aynısı olan binalardan oluşmasına; 
böylece savaşların ve terörist saldırıların yoğun olarak yaşandığı 21. yüzyılın dünyasında bu saldırıların hedefi haline gelmeden kendisine yeni bir yer bulmasına karşılık gelmektedir (Herzog ve De Meuron, 2008). Dolayısıyla, jenerik kent kuramı gibi, ayırt edilemez kent kuramı da kentin hiçbir yer ve her yer olma özelliği üzerine geliştirilmiştir. Bu, aynı zamanda, atopik kentin tipik özelliğidir.

$\mathrm{Bu}$ özelliğiyle atopik kent, modernizmin yanı sıra süpermodernizmle de ilişkilendirilebilir. 1990lı yılların şehirciliğini ve mimarlığını karakterize ettiği belirtilen süpermodernizm, modernizm gibi, kentlerin hiçbir yer ve her yer olarak tanımlanmasına yol açmışır (lbelings, 2002). Bu atopik kent tanımı, 2000li yıllarda süpermodernizmle yer değiştirmiş gibi görünen hipermodernizm bağlamında yeniden ele alınmaktadır. Hipermodernizmin 21. yüzyılın modernizmi olduğu belirtilmektedir (Ots, 2011). Hipermodernizm, modernizmin yerle kurduğu, çoğunlukla yok yer (no place) ya da yersizlik (placelessness) olarak ifade edilen ilişkiye yeni bir boyut kazandırmaktadır. Bu, sanal gerçeklik boyutudur. Hipermodernizm, sanal bir ortamda bilgisayar teknolojisi kullanılarak üretilen yeni bir yer ve yeni bir gerçeklik düzlemi oluşturur.

Tüm bunlar, bugün yeni bir kent ve yeni bir mimarlık dilinin oluştuğunu ortaya koymuştur. Bu dil, bugünün atopik kentini ve atopik mimarlığını ifade etmektedir. Ancak bu yazıda atopya New York, Los Angeles, Londra, Tokyo, İstanbul ya da Ankara gibi bugün genellikle metropol ya da mega kent olarak adlandırılan spesifik bir kentle ilişkilendirilmemektedir. Bunun yerine, atopik kentin bugünün jenerik kent modeli olduğuna işaret edilmektedir. Atopik kent, yerel ya da kültürel farklılıklardan bağımsız olarak, dünyanın her yerinde görülebilen kenttir. Başka deyişle, her türlü farklılığın nötralize edilmiş halidir. Bu nedenle, kentler aynılaşmaya ve sıradanlaşmaya; küresel bir kent modeli tanımlamaya başlamıştır.

Ancak küresellik kavramı son yıllarda yeniden tanımlanmış; küresel kente ve küresel dünyaya yönelik yeni kuramlar ortaya atılmıştır. Sloterdijk, foam-city kuramında hem kenti hem de dünyayı küresellik yerine daha çok köpük kavramıyla tartışmışır. Bugüne kadar küresel olarak tanımladığımız dünya, Sloterdijk'e göre, artık her şeyi ve herkesi kapsayan merkezi bir yaşam ortamı olmaktan çıkmıştır. Bugün bu ortamı tıpkı köpük gibi tek bir merkezi bulunmayan; çoğulluk, geçicilik ve değişkenlik esasına dayalı olan yerler oluşturmaktadır. Sloterdijk, bunu tekil değil çoğul bir küresellik olarak açıklamaktadır. Foam-world olarak tanımladığı bugünün dünyasının ise çoğul, geçici ve değişken yerler ve mekânlardan oluştuğunu ortaya koymaktadır (Sloterdijk, 2016/2016). 
$\mathrm{Bu}$ oluşum sürecinde bilgisayar teknolojisi önemli bir rol oynamaktadır. Ancak bu teknoloji, dünyanın farklı yerlerindeki kentleri aynı bilgisayar ekranuna taşımıştır. Böylece, Mitchell'in city of bits kuramında ortaya koyduğu gibi, yalnızca kentlerin değil bütünüyle dünyanın kendisi bilgisayar teknolojisiyle oluşturulan bir ağ (world wide web ya da www) halini almıştır. Bu kurama göre, city of bits, 21. yüzyılın kentini tanımlamaktadır. Yeni yüzyılın yeni kenti sanal mekânlardan oluşmaktadır (Mitchell, 1996). Dolayısıyla bilgisayarların yeni bir mekânsaldık ve yeni bir gerçeklik oluşturduğu ortaya çıkmaktadır. Bu, ekran düzleminde oluşturulan sanal bir gerçeklik ortamıdır (Virilio, 1999/2005).

Sanal gerçeklik ortamında nesnenin yerini imgesi almıştır. Nesne üretimi yerine daha çok imge üretimi yapılmaktadır. İmgenin artık bir üretim ve tüketim nesnesi olduğu anlaşılmaktadır. Bu nedenle, kentin ya da mimarlığın deneyiminden çok izleniminden söz edilmektedir. Burada sözü edilen izlenim, ekranda gördügümüz kentsel ya da mimari imgenin bizde bıraktı̆̆ etkiyle ilgilidir. Bugün imge etkisi, her zamankinden daha önemli hale gelmiştir. İzlenim, imge ve etkisi üzerinden edinilmektedir. Deneyim edinmek içinse gerçekten o yerde bulunmak, o yeri deneyimlemek gerekir. Ancak her yerin aynılaşmış ve ekran düzlemine taşınarak iki boyuta indirgenmiş olması yalnızca deneyimi izlenime dönüştürmekle kalmamış; yere ilişkin aynı izlenimlerin oluşmasına yol açmıştır. İmge, izlenim, siber mekân, data, hipermodernizm, sibernetik, iletişim ağları ve data peyzajı gibi kavramlar, atopik kentin yeni yüzyılda yerle ve teknolojiyle yeni bir ilişki kurduğuna işaret etmektedir. Ayrıca bu kavramlar, 1990lı yıllarda geliştirilen; bu yazıda ise daha çok 2000li yılların kentini ifade ettiği belirtilen atopik kentin ve kent dilinin değiştiğini göstermiştir (Şekil 2).

1990LAR

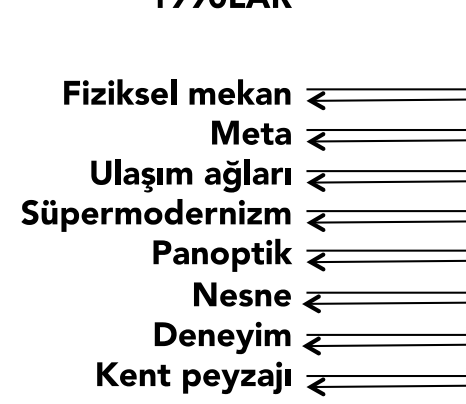

\section{LER}

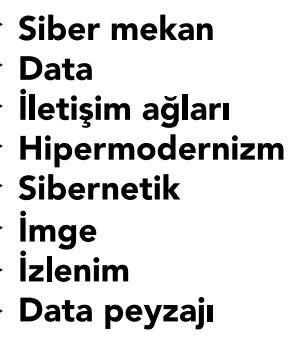

Şekil 2. 1990lı ve 2000li yıllarda atopik kent dilini oluşturan bazı kavramlar (Burada adı geçen kavramlar, yazarın yürüttüğü kuramsal araştırmalarda öne çımış olan kavramlardır. Bu nedenle atopik kentin değişen dili ve kuramı, bu kavramlar üzerinden tartışılmıştır. Bununla birlikte, atopik kent farklı kavramlarla tanımlanmaya ve tartışılmaya açıtır.) 


\section{Tartışma ve Sonuç}

Bu yazıda, atopik kent kuramı, 21. yüzyılın kentini tanımlayan bir kuram olarak tartışılmıştır. Tartışma, atopik kent kuramının ve onu oluşturan kavramların bu yüzyılın gerçeklerini, değerlerini ve değişkenlerini ifade ettiğini ortaya koymuştur. Bunun için, 20. yüzyılda geliştirilmiş olan atopik kent kuramının kavramsal çerçevesi değişmiş; bu kuramı oluşturan kavramlar, 21. yüzyılı ifade eden yeni ve teknoloji temelli kavramlarla yer değiştirmiştir. Atopik kent dilinin ve kuramının değişmesinin başlıca nedeni, bilgisayar teknolojisinin son yıllarda büyük bir hızla gelişmesi ve yaygın bir kullanım alanı edinmesidir. Öyle ki, bilgisayar teknolojisinde yaşanan gelişmeler, yeni bir atopik kent dilinin oluşmasını sağlamıştır.

Atopik kent dili bugün özellikle büyük kentlerin yapılaşma ve aynılaşma sürecini ifade etmektedir. Bu süreçte bilgisayar teknolojisi, kentsel ve mimari yapıları her yerde olan; belirli bir yeri ya da tanınır bir kimliği bulunmayan yapılar haline getirmiştir. Böylece bugünün atopik kentleri ortaya çıkmıştır. Kentlerin aynılaşma sürecinde küreselleşmenin de etkili olduğu bilinmektedir. Bununla birlikte, atopik kentlerin bugün daha çok dijitalleşmenin etkisiyle ortaya çıktığı görülmektedir. Bu nedenle, atopik kent dilini ve kuramını sibernetik, siber mekân, data ve data peyzajı gibi kavramlar oluşturmuştur. Bu kavramlar, kentlerin dijital bir ortamda; bu ortamın dijital araçlarıyla oluşturulduğunu ortaya koymuştur. Aynı ortamda ve aynı araçlarla oluşturulmaları kentleri aynılaştırmıştır. Kentlerdeki fiziksel, kültürel, toplumsal ve bireysel farklılıklar büyük ölçüde ortadan kalkmıştır. Yeni yüzyılın yeni teknolojileriyle üretilmiş olan atopik kent, küresel ve dijital bir kent modeli olarak karŞımıza çıkmıştır.

Atopik kentte üretim ve tüketim alışkanlıklarını daha çok bilgi ve iletişim teknolojileri oluşturmaktadır. Bu teknolojilerin sağlayıcısı olduğu sanal paylaşım ortamları, insanların farklı coğrafyalarda yaşasalar ve farklı kültürlere ya da geleneklere sahip olsalar da aynı şeyleri üretmesine, talep etmesine ve tüketmesine neden olmaktadır. Buna kentsel ve mimari ürünler ve üretimler de dahildir. Ancak bunlar, çoğu zaman, imgeleri bilgisayar ekranında üretilen ve ekran üzerinden tüketilen nesneler haline gelmektedir. İmgenin bir tüketim nesnesi haline gelmesi, imge üretiminin nesne üretiminin önüne geçmesini sağlamakla kalmamış; kentin imgesinin de bütünüyle değişmesine yol açmıştır.

Atopik kentin dili ve imgesi artık gelişmiş dijital teknolojiler kullanılarak oluşturulmaktadır. Bu oluşum sürecinde bilgisayarların genellikle tasarımcı 
rolünü üstlendiği sanılmaktadır. Ancak kentsel ve mimari tasarım, bilgisayar teknolojisini etkin ve yaygın olarak kullanan tasarımcilar tarafından yapılmaktadır. Bilgisayar destekli teknolojilerin kullanıldığı tasarım sürecinde yalnızca yeni formlar değil aynı zamanda yeni kavramlar ortaya çıkmaktadır. Bu kavramlar, kent ve mimarlık kuramlarının değişmesine ve yenilenmesine ya da yeni kuramların geliştirilmesine neden olmaktadır. Atopik kent kuramının ise kent, mimarlık ve teknoloji arasındaki değişken ve her geçen gün birbirini yeniden var eden ilişkiye göre kendisini yenilediği anlaşılmaktadır. Böylece atopik kent, bugün de güncel bir kent dili ve kuramı olma özelliğini korumaktadır. Bugünün kentini anlamak için öncelikle bu dili bilmek ve anlamak gerekir. Bu nedenle, yazı atopik kent dili ve bu dilin değişimi üzerine geliştirilmiştir. Gelecekte dünyada yeni atopyaların ortaya çıkabileceği düşünülürse, bu değişimin yalnızca bugünün değil geleceğin kent dilini de oluşturmak üzere yaşandığı söylenebilir. 


\title{
Extended Abstract
}

\section{Atopia, City and Technology: The Change of the Atopic City Language}

\author{
* \\ Gülşah Güleç \\ ORCID: 0000-0002-8041-2018
}

This paper discusses the changing relations of atopia, city and technology. But the aim of the discussion is not to offer or develop a new urban theory; rather, it is to reveal the fact that atopia defines the city of the 21st century. Atopia is not actually a new concept or a new theory. However, it is defined and discussed by new concepts due to the developments particularly in the computer technology. So, the changing atopic city language is discussed in the paper. Those changes prove the transformations of the relations of atopia, city and technology.

The concept of atopia is generally related to the concept of placelessness. Gregotti defines atopia as no place within the field of architecture (Gregotti, 2000/2016). In the architecture of the 1990s, every place such as shopping malls, gas stations, hotels, and airports are discussed as no places (Koolhaas, 1998). Atopia is therefore defined and discussed both as no place and every place. In the 2000s, it is still defined as no place and every place, but it has actually a new conceptual framework. That framework reveals the fact that concepts such as physical space, meta, transportation networks, supermodernism, panoptic, object, experience and cityscape are changed by the concepts of cyber space, data, communicational networks, hypermodernism, cybernetic, image, impression and datascape within the context of the atopic city of the 21st century. It is discussed in the paper that those conceptual changes are based on the changes in the relations of atopia, city and technology.

Besides, atopia defined as no place and every place is discussed by the concepts of banality and generality. That discussion is theorized in the generic city. Generic city is a technologic city, and it has very similar characteristics with the atopic city. It is even theorized as a kind of atopic city. According to 
Koolhaas, generic city is the city of the 21st century. And the dominant activity of that city is shopping. Everywhere is actually a shopping centre. It is therefore defined as nowhere by Koolhaas (Koolhaas, 1998). On the other hand, Herzog and De Meuron discuss that those popular urban theories become irrelevant in today's cities. They discuss that the cities of the 21st century wait for a new theorization and formation. But they also suggest that shopping is the main activity in the cities, as Koolhaas. Today's cities are formed within the framework of the shopping activity. Digital technology plays a really important role in that process; in other words, that technology leads a new urban model to be formed digitally. It refers to a new urban language as well. Indistinguishability and uniformity are some of the leading concepts of that language, and they point out to the fact that cities become the same places without identity. According to Herzog and De Meuron, it leads cities to be formed by the same buildings without any identifiable quality, and so they would not be exposed to the terrorist attacks or wars in the world of the 21st century (Herzog ve De Meuron, 2008). Their theory of indistinguishable city is therefore so similar to the theory of generic city, since they are both based on the urban quality defined as being nowhere and everywhere. It is actually the typical quality of the atopic city.

Those discussions reveal that a new city and a new city language are created recently. It is the language of today, not a fictionalized future. That language is created to define today's atopic city and atopic architecture. So, atopic city conceptually differs from utopic and distopic city. However, the concept of atopia defined as no place and every place, is not related to a specific city in the paper such as New York, Los Angeles, London, Tokyo, İstanbul or Ankara generally defined as metropolis or mega city. Instead, it is discussed that atopic city is the generic city of the 21st century. It is the city formed generally without any reference to the specific physical and cultural characteristics of the city or society. It refers to the fact that cities in the world today are very similar and even the same, and they define a global urbanity discussed here as the atopic city. As such, atopic city is a current urban model and theory. It is critically important to conceive and understand that theory to understand the new realities and dynamics of today's city.

\section{Kaynakça/References}

Barthes, R. (1994). Roland Barthes by Roland Barthes. (R. Howard, Çev.). California: University of California Press. (Orijinal eserin yaym tarihi 1977). 
Castells, M. (2007). Space of flows, space of places: Materials for a theory of urbanism in the information age. W. W. Braham, J. A. Hale (Der.), Rethinking technology: A reader in the architectural theory içinde (s. 441-456). New York, NY: Routledge.

Colas, A. (2005). Neoliberalism, globalisation and international relations. A. Saad-Filho, D. Johnston (Der.), Neoliberalism: A critical reader içinde (s. 70-79). London: Pluto Press.

Deleuze, G., Guattari, F. (1987). A thousand plateaus: Capitalism and schizophrenia. (B. Massumi, Çev.). Minneapolis: University of Minnesota Press. (Orijinal eserin yayın tarihi 1980).

Foucault, M. (1992). Hapishanenin doğuşu. (M. A. Kılıçbay, Çev.). Ankara: İmge Yayınları. (Orijinal eserin yayın tarihi 1975).

Frampton, K. (2008). Technoscience and environmental culture: A provisional critique. D. Kelbaugh, K. K. McCullough (Der.), Writing urbanism içinde (s. 333-344). New York, NY: Routledge.

Gausa, M., Guallart, V., Müller, W., Soriano, F., Porras, F., Morales, J. (2008). The metapolis dictionary of advanced architecture: City, technology and society in the information age. Barselona: Actar Publishers.

Gregotti, V. (2016). Mimarlı üzerine 17 mektup. (A. Tümertekin, Çev.). İstanbul: Janus Yayıncilık. (Orijinal eserin yayın tarihi 2000).

Herzog, J., De Meuron, P. (2008). How do cities differ? G. Mack (Der.), Herzog \& De Meuron 1997-2001: The complete works içinde (s. 241-244). Basel: Birkhäuser.

Ibelings, H. (2002). Supermodernism: Architecture in the age of globalization. Rotterdam: NAi Publishers.

Koolhaas, R. (1998). Generic city. New York, NY: The Monacelli Press.

Koolhaas, R. (2014). Absorbing modernity 1914-2014. R. Koolhaas (Der.), Fundamentals içinde (s. 1-6). Marsilio: 14th International Architecture Exhibition.

Leite, R. P. (2016). Atopic city: Consumption and death in urban life. Current Urban Studies, 4, 280-296.

Liu, H., Wei, X. ve Zhang, X. (2020). Datacenter city. 10 Aralı 2020 tarihinde https://www.aud.ucla.edu/student-work/archive/deep-urbanism adresinden erişildi.

Maas, W. (1999). Başlangıç. C. C. Davidson (Der.), Anytime içinde (s. 57-61). Ankara: Mimarlar Derneği Yayınları.

Millet, Y. (2013). Atopia \& aesthetics: A modal perspective. Contemporary Aesthetics, 11, 110.

MVRDV. (1999). Metacity / Datatown. 10 Aralık 2020 tarihinde https://www.mvrdv.nl/projects/147/metacity--datatown- adresinden erişildi.

Price, A. (2019, Şubat 12). The problem with helicopter urbanism. 10 Aralık 2020 tarihinde https://www.strongtowns.org/journal/2019/2/12/the-problem-with-helicopter-urbanism adresinden erişildi.

Ramchurn, R. (2014, Haziran 4). Fundamentals - Rem Koolhaas's research-led biennale. 10 Aralık 2020 tarihinde https://www.architectsjournal.co.uk/archive/fundamentals-rem-koolhaass-research-led-biennale adresinden erişildi. 
Ricci, T. (2020, Ocak 17). Toronto on track to have more skyscrapers than Chicago, but will quality match quantity? 10 Aralık 2020 tarihinde https://www.cbc.ca/news/canada/toronto/toronto-skyscrapers-chicago-1.5429816 adresinden erişildi.

Ots, E. (2011). Decoding theoryspeak: An illustrated guide to architectural theory. New York, NY: Routledge.

Sloterdijk, P. (2016). Foams: Spheres volume III. (W. Hoban, Çev.). Los Angeles, LA: Semiotext(e). (Orijinal eserin yayin tarihi 2016).

Virilio, P. (2005). The information bomb. (C. Turner, Çev.). New York, NY: Verso Books. (Orijinal eserin yayın tarihi 1999).

William, M. J. (1996). City of bits: Space, place, infobahn. Londra: The MIT Press 